\title{
An Open-Source Tool to Facilitate the Processing of GRACE Observations and GLDAS Outputs: An Evaluation in Bangladesh
}

\section{OPEN ACCESS}

Edited by:

Ashutosh S. Limaye,

National Aeronautics and Space Administration (NASA), United States

Reviewed by:

Hyongki Lee

University of Houston, United States Augusto Getirana,

National Aeronautics and Space Administration, United States

*Correspondence:

Cédric H. David cedric.david@jpl.nasa.gov

Specialty section:

This article was submitted to

Freshwater Science,

a section of the journal

Frontiers in Environmental Science

Received: 31 May 2019

Accepted: 25 September 2019

Published: 23 October 2019

Citation:

Purdy AJ, David CH, Sikder MS

Reager JT, Chandanpurkar HA, Jones NL and Matin MA (2019) An

Open-Source Tool to Facilitate the Processing of GRACE Observations and GLDAS Outputs: An Evaluation in

Bangladesh.

Front. Environ. Sci. 7:155 doi: 10.3389/fenvs.2019.00155

\begin{abstract}
Adam J. Purdy 1,2, Cédric H. David ${ }^{1 *}$, Md. Safat Sikder ${ }^{1}$, John T. Reager ${ }^{1}$, Hrishikesh A. Chandanpurkar ${ }^{1}$, Norman L. Jones ${ }^{3}$ and Mir A. Matin ${ }^{4}$
\end{abstract}

1 Jet Propulsion Laboratory, California Institute of Technology, Pasadena, CA, United States, ${ }^{2}$ Department of Environmental Science, University of San Francisco, San Francisco, CA, United States, ${ }^{3}$ Department of Civil and Environmental Engineering, Brigham Young University, Provo, UT, United States, ${ }^{4}$ International Centre for Integrated Mountain Development, Kathmandu, Nepal

Bangladesh lies at the intersection of the Ganges, Brahmaputra, and Meghna rivers with a combined average discharge of $38,000 \mathrm{~m}^{3} \mathrm{~s}^{-1}$ ranking fourth globally. Despite the volume of water flowing through and seasonally inundating parts of the landscape, groundwater reliance is necessary to support an intensive agricultural industry. Here we use newly-developed open-source software to combine observations from the Gravity Recovery and Climate Experiment (GRACE) satellites with hydrologic estimates of land water storage from the Global Land Assimilation Data System (GLDAS) to isolate basin-scale groundwater anomalies in Northwest Bangladesh from 2002 to 2016 . We place our estimates in the context of previously-published water management estimates and our results suggest the largest losses in water storage are due to groundwater abstractions with groundwater storage decreasing at a rate of $0.88 \mathrm{~cm} \mathrm{yr}^{-1}$. We estimate basin-averaged total water storage loss from 2002 to 2016 at $27.92 \mathrm{~cm}$ with groundwater and surface water storage loss accounting for $12.46 \mathrm{~cm}$ or $44.6 \%$. For Bangladesh, a region where $80 \%$ of landcover is dedicated for agricultural use and over half of the country's population is employed in the agricultural sector, the estimated declines in water storage hold long-term implications for the livelihood and food supply of the region.

Keywords: water resources, groundwater, sustainable management, food security, open-source software

\section{INTRODUCTION}

Having a holistic understanding of water availability is necessary to combat the challenges of managing water resources under a changing climate (Famiglietti and Rodell, 2013; Rodell et al., 2018). With evidence of more intense rainfall (Durack et al., 2012), an increased probability of flooding (Milly et al., 2002), decreasing glacier melt (Gardner et al., 2013), changes in seasonal snowpack (Smith and Bookhagen, 2018), and shifts in the intensity of drought (Trenberth et al., 2014), water managers require as much relevant information as possible to meet water needs of a growing populations to support food and energy production (Vörösmarty et al., 2000; Milly et al., 2005). Traditionally humans have met agricultural and urban water demands by routing surface water or pumping groundwater. While in situ surface water observations have provided rich datasets to support management (Fekete et al., 2012), limited observations of groundwater 
have prevented a complete understanding of water availability and use to support sustainable management (Taylor et al., 2013; Famiglietti, 2014).

Globally, groundwater provides a drinking water source for half of the world (IGRAC, 2018) and supports over $40 \%$ of irrigated lands worldwide (Siebert et al., 2010). While groundwater use varies greatly region to region depending on infrastructure and climate, all regions increase reliance under drought (Famiglietti et al., 2011; Castle et al., 2014). With 5 billion people expected to feel the impacts on freshwater availability from a changing climate, regions that are already overreliant on groundwater will be more susceptible to devastating consequences of degraded quality and reduced availability (Vörösmarty et al., 2000). Unfortunately, many regions still lack the infrastructure to monitor changes in availability across basins scales.

In 2002, with the launch of the Gravity Recovery And Climate Experiment (GRACE) mission (Tapley et al., 2004), the global extent of this shared problem of over-reliance on groundwater began to emerge (Famiglietti et al., 2011; Voss et al., 2013; Richey et al., 2015). Numerous studies have utilized GRACE observations of terrestrial water storage anomalies (TWSa), the combined anomalies of snow, soil moisture, canopy water, surface water, and groundwater, to study the global water cycle and impacts on water resources (Equation 1).

$$
T W S a=S M a+S W E a+C A N a+S W a+G W a
$$

where, $S M a$ is soil moisture anomaly, $S W E a$ is the snow water equivalent anomaly, $\mathrm{CANa}$ is canopy intercepted water anomaly, and $S W a$ is surface water storage anomaly. GRACE observations have supported quantifying: flood potential (Reager and Famiglietti, 2009), drought (Thomas et al., 2014), basin evapotranspiration (Rodell et al., 2011), global discharge (Chandanpurkar et al., 2017), and the fingerprint of human management on the water cycle at basin scales (Anderson et al., 2012; Castle et al., 2016; Massoud et al., 2018). GRACE's unique ability to quantify total terrestrial water storage anomalies facilitates tracking rates of groundwater depletion across the globe (Famiglietti, 2014). From India and the Middle East to the California Central Valley and Colorado River Basin, GRACE observations have revealed how each region relies on groundwater to meet freshwater demands from irrigated farmland, industry, and growing populations (Rodell et al., 2009; Famiglietti et al., 2011; Voss et al., 2013; Castle et al., 2014). Many of the regions with evidence of water loss have limited surface water availability, other regions, such as Bangladesh, show evidence of persistent storage declines despite high rates of mean annual rainfall and river discharge (Shamsudduha et al., 2012; Burgess et al., 2017).

Bangladesh lies at the confluence of the Ganges, Brahmaputra, and Meghna Rivers with a mean discharge topping 38,000 $\mathrm{m}^{3} \mathrm{~s}^{-1}$ (Gain et al., 2011). The volume of water flowing in these rivers makes up large fraction of the total water within the country (Getirana et al., 2017). Furthermore, Bangladesh experiences seasonally intense rainfall during the monsoon season from June to September (Dash et al., 2012). In fact, some Eastern parts of the country experience more than $2 \mathrm{~m} \mathrm{yr}^{-1}$ of annual rainfall, among the highest rates in the world. Despite seasonal inundations on much of the landscape, a large agriculture industry relies on groundwater to irrigate farmland (Figure 1). In Bangladesh, where over 160 million people live, more than half the population relies on agriculture to support their livelihood (Food Agriculture Organization, 2011). The importance of agriculture to sustain food production and local workforces places a strain on regional water resources. Previous in situ measurements of documented declines in groundwater spurred legislation in 1999 and 2001 to curtail over-use (Food Agriculture Organization, 2011). The Northwest Region is home to the highest fractions of irrigated farmland in the country and relies heavily on groundwater during the dry season to maintain crop production. Unfortunately, this happens to be the area in Bangladesh most susceptible to drought and its impacts (Dey et al., 2012; Alamgir et al., 2015). Water management challenges in Bangladesh are compounded by water contamination (e.g., arsenic) and salinity intrusion (Nickson et al., 2000; Mahmuduzzaman et al., 2014). During prolonged dry years the arsenic-rich groundwater being pumped to the surface for irrigation accumulates in soils used to grow rice (Roberts et al., 2010). In addition, projected increases in peak flow intensity may limit this region's ability to store surface water (Gain et al., 2011). Like many similar regions around the world

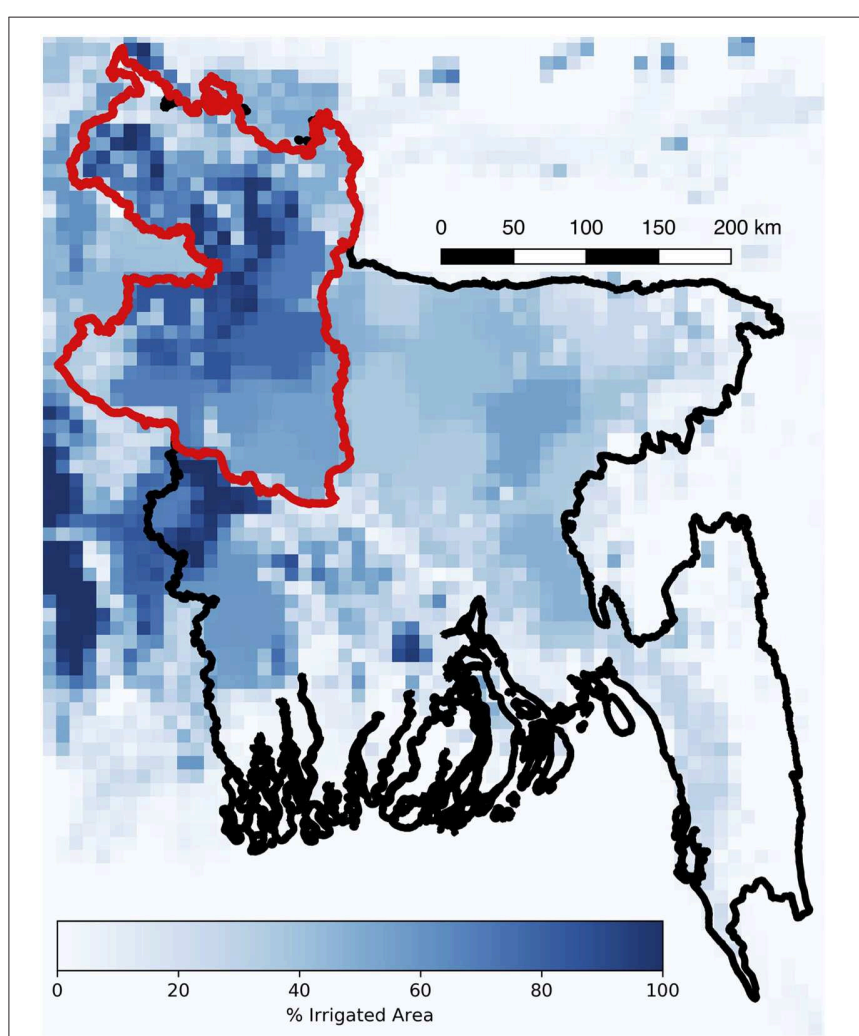

FIGURE 1 | Fraction of irrigated area in Bangladesh (Siebert et al., 2013). Country boundary in black, Northwest Bangladesh region (i.e., Rangpur and Rajshahi divisions) boundary in red. The irrigated area data were accessed from FAO AQUASTAT http://www.fao.org/nr/water/aquastat/irrigationmap/. 
facing complex water management challenges, regional scale observations of water storage changes hold potential to support long-term planning (Adhikary et al., 2013).

Here we use 159 months of GRACE data, from April 2002 through January 2017, to evaluate water storage changes in Bangladesh. To isolate changes in groundwater storage we supplement GRACE observations with model estimates of soil moisture, snow, and canopy storage. While GRACE observations (2002-2007) have been demonstrated to accurately capture the seasonal water cycle including the monsoon intensity over the entire Bengal Basin (Steckler et al., 2010; Shamsudduha et al., 2012), regions with the most intense groundwater use have yet to be analyzed in isolation and the shorter records used in previous analysis limited the computation of regional trends. In addition to a national scale analysis over Bangladesh, we focus additional analysis on Northwest Bangladesh where irrigated farmland and groundwater use is among the highest in the country (Figure 1). Furthermore, we here present the Satellite Hydrology Bits Analysis and Mapping (SHBAAM), an entirely open-source python-based tool, to perform regional-scale water budget analysis using GRACE observations and model data for a given region of interest.

\section{DATA AND METHODS}

\section{Study Region}

In Rangpur and Rajshahi, the two Divisions that make up Northwest Bangladesh (Figure 1), groundwater is the predominant source of water for irrigation. Compared to the rest of the country, this region experiences substantially less rainfall (Dash et al., 2012). Northwest Bangladesh is bordered to the South by the Padma River, the main distributary of the Ganges River, to the West and North by India, and to the East by the Jamuna River, the lower course of the Brahmaputra River. While seasonal inundation occurs within the floodplains of these major rivers, farmers still pump groundwater during the dry season to support crops such as rice, wheat, potato and fruits including lychees and mangos, among others (Food Agriculture Organization, 2011). On top of the large presence of agriculture, Bangladesh is one of the most densely populated countries in the world with more than 1,100 people per $\mathrm{km}^{2}$. These two factors exacerbate stress on water resources and create a need to bring the regional water back into balance.

\section{GRACE Terrestrial Water Storage Observations}

In this analysis, we use the Jet Propulsion Laboratory Release 5 GRACE mascon solutions from April 2002 through January 2017 (Watkins et al., 2015). This dataset provides mass equivalent terrestrial water storage (TWS) anomalies on a $0.5^{\circ}$ grid. Gain factors, generated with CLM4 model outputs, were used as multiplying factors along with the GRACE TWS anomalies to minimize leakage errors and distribute mass changes within each $3^{\circ}$ mascon solution (Wiese et al., 2016). Additionally, we remove the temporal mean for the entire time period and present TWS anomalies relative to the complete record from 2002 to 2017. To evaluate changes in all the components of the water budget, we supplement GRACE observations with model estimates of snow water equivalent, canopy storage, soil moisture storage, and surface water storage; as discussed below.

\section{GLDAS Land Surface Model Elements}

Outputs from the Global Land Data Assimilation System (GLDAS, Rodell et al., 2004) provide multiple land surface model (LSM) estimates globally. GLDAS utilizes observationbased forcing datasets of precipitation and radiation to run land surface models at 3-hourly timesteps to globally resolve fluxes and storage of water and energy. We use monthly outputs from four models within GLDAS including: Noah (NOAH) (Chen et al., 1996, 1997; Ek, 2003), Variable Infiltration Capacity (VIC) (Liang et al., 1994), Common Land Model (CLM) (Dai et al., 2003), and Mosaic (MOS) (Koster et al., 2000). Each LSM provides an independent estimate of snow water equivalent, soil moisture, and canopy water storage. While each LSM uses the a common set of soil types and atmospheric forcing, the maximum depth of soil water storage varies from $1.9 \mathrm{~m}$ (VIC), $2.0 \mathrm{~m}$ (NOAH), $3.0 \mathrm{~m}$ (MOS), to 3.43 meters (CLM), and the total number of layers ranges from 3 (VIC and MOS), 4 (NOAH), to 10 (CLM). Surface water storage, such as lakes, reservoirs, and rivers, is not directly resolved by any of the GLDAS models. Instead, we apply the Routing Application for Parallel computation of Discharge (RAPID) river routing model (David et al., 2011) to estimate mean surface water storage for each GLDAS model across every reach in the Ganges, Brahmaputra, and Meghna Basins (Sikder et al., in press). Sikder et al. (in press) simulated 3-hourly discharge using all GLDAS models for the Ganges-Brahmaputra-Meghna Basin on a 15arc second river network from HydroSHEDS (Lehner et al., 2008). These discharge simulations result in standard errors $\leq 2 \%$ with correlation coefficients ranging from 0.6 for the Meghna River to 0.8 for the Brahmaputra River. We sum the volume from all the river reaches within Bangladesh and compute monthly mean surface water storage and associated uncertainty using multi-model statistics (Richey et al., 2015; Thomas et al., 2017). To compare LSM and river routing outputs with GRACE TWS anomalies, each storage component was converted to an equivalent water height anomaly by removing the temporal mean from April 2002 to January 2017 and dividing by the surface area.

\section{Computing Groundwater Anomalies With SHBAAM}

The Satellite Hydrology Bits Analysis and Mapping (SHBAAM) software developed here completes the pre and post-processing tasks on GRACE TWS anomalies that are necessary to study the terrestrial water cycle and compute changes in groundwater. SHBAAM is an open-source Python and bash shell toolbox that is available online via GitHub (https://github.com/c-h-david/ shbaam) or Docker (https://hub.docker.com/r/chdavid/shbaam). This toolbox automates the downloading and processing of the GRACE and GLDAS datasets to evaluate changes in water storage for any region around the globe. Groundwater anomalies for a given region are computed by rearranging (Equation 1):

$$
G W a=T W S a-S M a-S W E a-C A N a-S W a
$$


SHBAAM simplifies this computation by preparing and subsetting the necessary prerequisite data to the same temporal resolution and spatial domain. Scripts retrieve GRACE terrestrial water storage anomalies, land-ocean masks, and gain factors from the Physical Oceanography Distributed Active Archive Center (PO.DAAC), and individual monthly GLDAS snow water equivalent, soil moisture, and canopy storage from the Goddard Earth Science Data and Information Service Center (GES-DISC). Missing GRACE observations are automatically filled according to Hamlington et al. (2019). First, GRACE TWSa data are multiplied by spatially distributed gain factors. Then the scaled TWSa data are detrended and the annual climatology is removed. Gaps in the remaining data, the interannual variation, are filled using cubic interpolation. Lastly, the climatology and trend are reintroduced to provide a continuous TWSa record. These gap-filling steps provide more accurate estimates of missing observations during winter maximums and summer minimums. Additional processing steps include concatenation of the individual monthly GLDAS LSM outputs and LSM anomaly computation to compare with GRACE TWS anomaly observations. Any shapefile in a geographic coordinate reference system can be used in SHBAAM for the joint regional analysis of GRACE and GLDAS. SHBAAM finds the intersecting grid coordinates for both GRACE and GLDAS and computes area-weighted averages for each water storage component to determine groundwater storage anomalies within the domain following (Equation 2). Groundwater anomalies are computed using the multi-model mean values. Outputs from SHBAAM include tables of monthly water storage anomalies and figures of the time-series changes in each component (Figure 2). These output tables support supplemental analyses on basin water storage changes, such as trend analysis or quantifying the total volume of water lost.

Error variances in $S W E a, S M a$, and $C A N a$ are computed using the multi-model standard deviation. The errors in TWSa are on average $7 \mathrm{~cm}$ for the study region. Errors in monthly groundwater assume the absence of error covariances and are computed as:

$$
\begin{aligned}
& \sigma G W a= \\
& \sqrt{(\sigma T W S a)^{2}-(\sigma S M a)^{2}-(\sigma S W E a)^{2}-(\sigma C A N a)^{2}-(\sigma S W a)^{2}}
\end{aligned}
$$

where $\sigma X a$ is the standard deviation or error variance in each hydrologic component $X$. SHBAAM can be used to reproduce the results from this study or to complete similar analyses on any basin globally granted that the basin size is large-enough to be used along with GRACE data.

\section{RESULTS}

Hydrographs for each water storage component from GRACE and GLDAS reveal variations in water storage and similar annual amplitudes for terrestrial water storage and soil moisture (Figure 2). In both Bangladesh and Northwest Bangladesh snow water equivalent and canopy water storage anomalies are negligible. The SHBAAM outputs show declines in GRACE terrestrial water storage anomalies from 2002 to 2017 for both

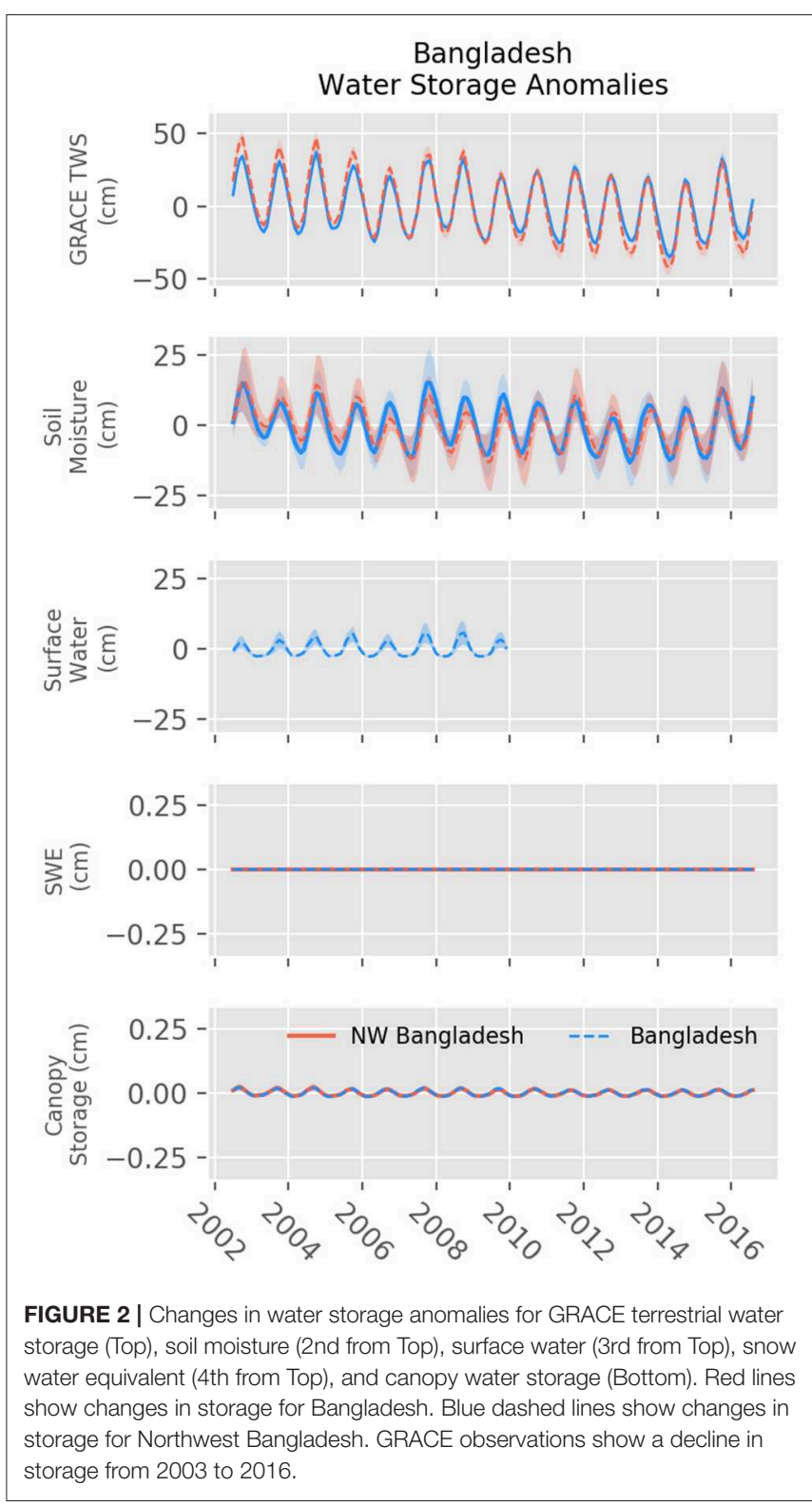

Bangladesh and Northwest Bangladesh. Trends in TWSa reveal average storage declines at a rate of $-0.85 \mathrm{~cm} \mathrm{yr}^{-1}\left(-1.16 \mathrm{~km}^{3}\right.$ $\left.\mathrm{yr}^{-1}\right)$ and $-1.99 \mathrm{~cm} \mathrm{yr}^{-1}\left(-0.60 \mathrm{~km}^{3} \mathrm{yr}^{-1}\right)$, respectively. Soil moisture anomalies show similar declines from 2002 to 2015, but a recovery in 2016. Non-zero trends for each water storage component are listed in Table 1. We estimate total storage lost for each region using the trend of decline and the area. From 2002 to 2017 GRACE observations reveal Bangladesh lost a total of $16.26 \mathrm{~km}^{3}$ freshwater. During the same time period we find the Northwest Region lost $8.42 \mathrm{~km}^{3}$ of water. Outputs from SHBAAM reveal two hot-spots of water decline in the Northwest region (Figure 3).

Groundwater anomalies uncover large declines in storage across the time period (Figure 4). Groundwater storage decreases across Bangladesh at a rate of $-0.75 \mathrm{~cm} \mathrm{yr}^{-1}\left(-1.02 \mathrm{~km}^{3}\right.$ 
$\mathrm{yr}^{-1}$ ) and in Northwest Bangladesh at a rate of $-0.88 \mathrm{~cm} \mathrm{yr}^{-1}$ $\left(-0.27 \mathrm{~km}^{3} \mathrm{yr}^{-1}\right)$. These rates are consistent with previously published ranges of in situ estimates $\left(-0.85\right.$ to $\left.-1.61 \mathrm{~km}^{3} \mathrm{yr}^{-1}\right)$ (Shamsudduha et al., 2012). During the study period, Bangladesh lost approximately $14.3 \mathrm{~km}^{3}$ with the Northwest region accounting for roughly $3.74 \mathrm{~km}^{3}$. Interestingly, we find changes in surface water storage anomalies, as computed from routed

TABLE 1 | Trends for water storage components in Bangladesh and Northwest Bangladesh.

\begin{tabular}{lll}
\hline Component & Bangladesh & Northwest Bangladesh \\
\hline Total Water Storage & $-0.890 \mathrm{~cm} \mathrm{yr}^{-1}$ & $-2.24 \mathrm{~cm} \mathrm{yr}^{-1}$ \\
Soil Moisture & $-0.134 \mathrm{~cm} \mathrm{yr}^{-1}$ & $-1.355 \mathrm{~cm} \mathrm{yr}^{-1}$ \\
Groundwater & $-0.755 \mathrm{~cm} \mathrm{yr}^{-1}$ & $-0.886 \mathrm{~cm} \mathrm{yr}^{-1}$ \\
\hline
\end{tabular}

Trends are computed for 2003-2016. Trends of $0 \mathrm{~cm} \mathrm{yr}^{-1}$ are not displayed for canopy water storage or snow water equivalent.
GLDAS runoff do not change the trajectory of Bangladesh-wide changes in groundwater anomalies (Supplementary Figure 1). The Rangpur and Rajshahi Divisions lie in regions more susceptible to pre-monsoon and post-monsoon droughts and are known to rely more heavily on groundwater to irrigate farmland.

We compare changes in water storage and groundwater storage for all of Bangladesh to published values for 2008 (Food Agriculture Organization, 2011). Previously reported total water withdrawal for 2008 is estimated at $35.87 \mathrm{~km}^{3}$, with groundwater extraction accounting for approximately $80 \%$ or $28.42 \mathrm{~km}^{3}$. The same report estimates groundwater recharge to be $21 \mathrm{~km}^{3}$ $\mathrm{yr}^{-1}$. Here we estimate the amplitude of groundwater storage for 2007, 2008, and the mean climatology for the GRACE record to be $30.7,36.0$, and $27.6 \mathrm{~km}^{3}$, respectively (Figure 5). Our estimates are therefore of the same order of magnitude as study previous, although they notably differ by over $30 \%$. This disagreement can be attributed to numerous factors, including: (1) a potential underestimation in water withdrawal estimates used previously for the region or (2) known limitations in the
A

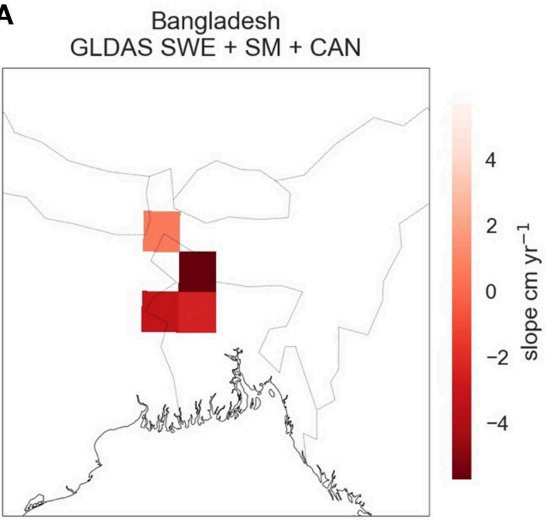

B

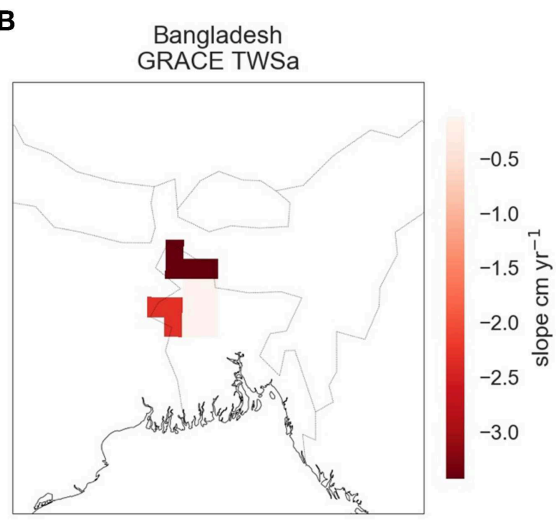

FIGURE 3 | Changes in water storage represented as the slope from 2002 to 2017 for the sum of GLDAS water storage components (A) and GRACE total water storage (B). The plots demonstrate the difference in spatial resolution of the two datasets (GLDAS $1^{\circ}$ and GRACE $0.5^{\circ}$ ).

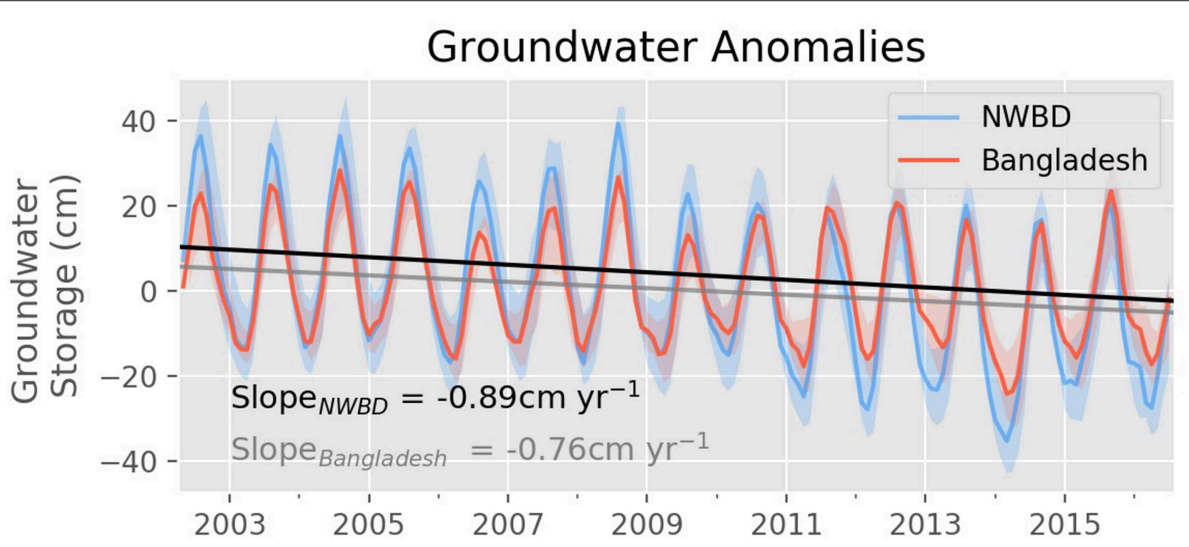

FIGURE 4 | Changes in groundwater anomalies for Bangladesh (red line) and Northwest Bangladesh (blue line). Slopes for Bangladesh (gray) and Northwest Bangladesh (black) show a decline in groundwater from 2002 to 2017. Shaded regions represent monthly groundwater uncertainty for each study region as computed by Equation (3). 


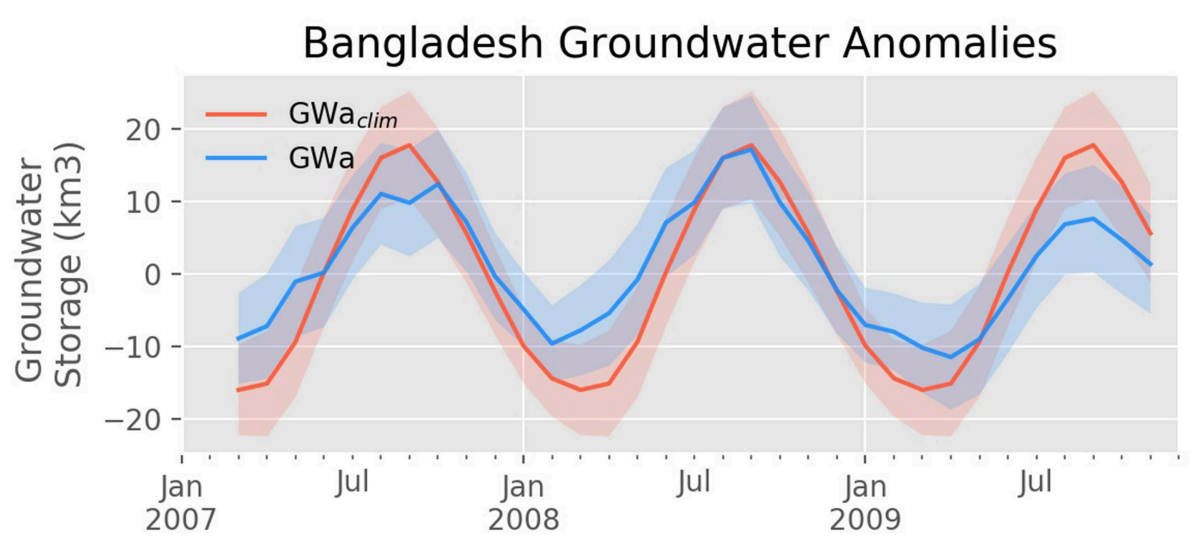

FIGURE 5 | Changes in groundwater storage with uncertainty for Bangladesh. The blue line indicates the monthly changes in groundwater storage and the red line indicates the corresponding monthly climatology. Shaded regions represent monthly groundwater uncertainty as computed by Equation (3).

combination of GRACE and GLDAS to estimate changes in groundwater storage (Scanlon et al., 2018), (3) high uncertainty in surface water storage anomalies, or (4) natural aquifer recharge and discharge processes make up for the difference. Nonetheless, our methodology provides an alternative means to estimating regional water storage changes from remotely-sensed observations combined with global hydrologic simulations, and is here indicative of over-consumptive use.

\section{DISCUSSION}

Despite large amounts of annual discharge from the Ganges, Brahmaputra, and Meghna, GRACE observations suggest that intense agricultural practices sustained water storage declines from 2002 to 2017 in Bangladesh. Previous exploration of this regional signal found changes in precipitation being the driving cause for total water storage declines (Rodell et al., 2018). Here, we find evidence that groundwater depletion contributes to this regional signal, especially in Northwest Bangladesh. Despite observations and model estimates indicating potentially dire circumstances, further on-ground validation is required to validate the magnitude of potential groundwater over-reliance. Recent work revealed GRACE observations and GLDAS modeled total water storage disagree on trend direction across the majority of global river basins (Scanlon et al., 2018). We found consistent trends across models in Northwest Bangladesh but contrasting trends across the Bangladesh study region (Supplementary Figure 2). Multi-model statistics help quantify the uncertainty in the monthly GWa estimates but relating the SHBAAAM outputs to previous studies can reveal opportunities to further improve these estimates. For example, the ratio of SWSa to TWSa estimated by GLDAS is lower than previous studies using the Noah-MP model with HyMAP river routing (Getirana et al., 2017). Further efforts to quantify seasonal and inter-annual surface water storage anomalies in the region may shed a clearer light on the degree of severity for particular regions.

While the uncertainty of groundwater anomalies computed with GRACE increases for smaller scale analyses, our results still capture trends and spatial patterns of groundwater reliance similar to previous in situ analysis for the region (Shamsudduha et al., 2012). The findings from this study suggest groundwater use exceeds natural recharge rates in Bangladesh extending to as recently as 2017, especially in the Rangpur and Rajshah Divisions. For this region, projected changes in surface discharge pose to only further complicate regional water management by increasing seasonal groundwater reliance and increasing the difficulty of storing surface water with larger peak flows. In addition to these potential challenges in managing freshwater quantity, Bangladesh also faces rising sea levels that intrude on coastal aquifers, and arsenic accumulation in farm soils during dry spells (Roberts et al., 2010; Mahmuduzzaman et al., 2014). These local issues mirror similar challenges faced around the world that require as much information as possible to understand and plan for actionable solutions.

GRACE and GLDAS-based hydrologic estimates provide a potential tool for water managers to support long-term management strategies by evaluating regional changes with relatively low latency, constraining basin-scale modeled estimates, and identifying regions facing or moving toward severe water shortages. The outputs from SHBAAM are not meant to replace in situ monitoring as many water management decisions are made at scales finer than the GRACE satellites can resolve. Instead, these datasets hold potential to support regional and seasonal management by complementing efforts focused on short-term forecasting of transboundary water flows (e.g., Biancamaria et al., 2011). SHBAAM lowers the barriers to access and use of these NASA datasets to support water management and scientific research. The increased exposure to these datasets may lead to new, creative avenues for water managers to harness the value of this tool and relevant associated datasets.

Since its generation, successful SHBAAM tutorials have been given to trainers at international agency partners through the NASA SERVIR program. However, creating and maintaining open-source software such as SHBAAM does not come without challenges. Hosting the toolbox and documentation on Github and Docker reduces many of the challenges such as installation requirements for different operating systems. Recent effort has 
moved toward simplifying the coding interface through the introduction of Python-backed notebooks. These steps can be expected to further broaden the user base, and overcome a general lack of familiarity around command line interfaces outside of the research community. Additionally, with the recently launched GRACE-Follow On and improvements to GLDAS, updates to SHBAAM processing will be required to leverage near-real time observations and guide water management into the next decade (Tapley et al., 2019).

\section{DATA AVAILABILITY STATEMENT}

The software and datasets generated for this study can be found in the https://github.com/c-h-david/shbaam. Data downloaded by this software are freely available with a NASA EarthData Login. GRACE data are available at https://podaac-opendap.jpl. nasa.gov. GLDAS model output are available at https://disc.gsfc. nasa.gov.

\section{REFERENCES}

Adhikary, S. K., Das, S. K., Saha, G. C., and Chaki, T. (2013). "Groundwater drought assessment for barind irrigation project in Northwestern Bangladesh," in 20th International Congress on Modelling and Simulation, At Modelling and Simulation Society of Australia and New Zealand (Adelaide, SA).

Alamgir, M., Shahid, S., Hazarika, M. K., Nashrrullah, S., Harun, S. B., et al. (2015). Analysis of meteorological drought pattern during different climatic and cropping seasons in bangladesh. J. Am. Water Resour. Assoc. 51, 794-806 doi: $10.1111 /$ jawr.12276

Anderson, R. G., Lo, M.-H., and Famiglietti, J. S. (2012). Assessing surface water consumption using remotely-sensed groundwater, evapotranspiration, and precipitation. Geophys. Res. Lett. 39, 1-6. doi: 10.1029/2012GL 052400

Biancamaria, S., Hossain, F., and Lettenmaier, D. P. (2011). Forecasting transboundary river water elevations from space. Geophys. Res. Lett. 38:L11401. doi: 10.1029/2011GL047290

Burgess, W. G., Shamsudduha, M., Taylor, R. G., Zahid, A., Ahmed, K. M., Mukherjee, A., et al. (2017). Terrestrial water load and groundwater fluctuation in the Bengal Basin. Sci. Rep. 7:3872. doi: 10.1038/s41598-017-04159-w

Castle, S. L., Reager, J. T., Thomas, B. F., Purdy, A. J., Lo, M. H., Famiglietti, J. S., et al. (2016). Remote detection of water management impacts on evapotranspiration in the Colorado River Basin. Geophys. Res. Lett. 43, 5089-5097. doi: 10.1002/2016GL068675

Castle, S. L., Thomas, B. F., Reager, J. T., Rodell, M., Swenson, S. C., and Famiglietti, J. S. (2014). Groundwater depletion during drought threatens future water security of the Colorado River Basin. Geophys. Res. Lett. 41, 5904-5911. doi: 10.1002/2014GL061055

Chandanpurkar, H. A., Reager, J. T., Famiglietti, J. S., and Syed, T. H. (2017). Satellite- and reanalysis-based mass balance estimates of global continental discharge (1993-2015). J. Clim. 30, 8481-8495. doi: 10.1175/JCLI-D-16-0708.1

Chen, F., Janji,ć, Z., and Mitchell, K. (1997). Impact of atmospheric surface-layer parameterizations in the new land-surface scheme of the NCEP mesoscale Eta model. Boundary Layer Meteorol. 85, 391-421. doi: 10.1023/A:100053 1001463

Chen, F., Mitchell, K., Schaake, J., Xue, Y., Pan, H. L., Koren, V., et al. (1996). Modeling of land surface evaporation by four schemes and comparison with FIFE observations. J. Geophys. Res. Atmos. 101, 7251-7268. doi: 10.1029/95JD02165

Dai, Y., Zeng, X., Dickinson, R. E., Baker, I., Bonan, G. B., Bosilovich, M. G., et al. (2003). The common land model. Bull. Am. Meteorol. Soc. 8:1013-1024. doi: 10.1175/BAMS-84-8-1013

\section{AUTHOR CONTRIBUTIONS}

$\mathrm{CD}$ and MM conceived this study. AP, CD, and MS completed this analysis. All authors contributed to writing the manuscript.

\section{FUNDING}

AP, CD, MS, JR, and HC were supported by the Jet Propulsion Laboratory, California Institute of Technology, under a contract with NASA, including a grant from the SERVIR Applied Sciences Team. MM was supported by USAID under SERVIR HKH at ICIMOD.

\section{SUPPLEMENTARY MATERIAL}

The Supplementary Material for this article can be found online at: https://www.frontiersin.org/articles/10.3389/fenvs. 2019.00155/full\#supplementary-material

Dash, B. K., Rafiuddin, M., Khanam, F., and Islam, M. N. (2012). Characteristics of meteorological drought in Bangladesh. Nat. Hazards. 64, 1461-1474. doi: 10.1007/s11069-012-0307-1

David, C. H., Maidment, D. R., Niu, G.-Y., Yang, Z.-L., Habets, F., and Eijkhout, V. (2011). River network routing on the NHDPlus dataset. J. Hydrometeorol. 12, 913-934. doi: 10.1175/2011JHM1345.1

Dey, N., Alam, M., Sajjan, A., Bhuiyan, M., Ghose, L., Ibaraki, Y., et al. (2012). Assessing environmental and health impact of drought in the Northwest Bangladesh. J. Environ. Sci. Nat. Resour. 4, 89-97. doi: 10.3329/jesnr.v4i2.10141

Durack, P. J., Wijffels, S. E., and Matear, R. J. (2012). Ocean salinities reveal strong global water cycle intensification during 1950 to 2000. Science 27, 455-458. doi: $10.1126 /$ science. 1212222

Ek, M. B. (2003). Implementation of Noah land surface model advances in the National Centers for Environmental Prediction operational mesoscale Eta model. J. Geophys. Res. 108:8851. doi: 10.1029/2002JD003296

Famiglietti, J. S. (2014). The global groundwater crisis. Nat. Clim. Chang. 4, 945-948. doi: 10.1038/nclimate2425

Famiglietti, J. S., Lo, M., Ho, S. L., Bethune, J., Anderson, K. J., Syed, T. H., et al. (2011). Satellites measure recent rates of groundwater depletion in California's Central Valley. Geophys. Res. Lett. 38:L03403. doi: 10.1029/2010GL046442

Famiglietti, J. S., and Rodell, M. (2013). Water in the balance. Science 340, 1300-1301. doi: 10.1126/science. 1236460

Fekete, B. M., Looser, U., Pietroniro, A., and Robarts, R. D. (2012). Rationale for monitoring discharge on the ground. J. Hydrometeorol. 12, 1977-1986. doi: 10.1175/JHM-D-11-0126.1

Food and Agriculture Organization (2011). Irrigation in Southern and Eastern Asia in Figures: AQUASTAT Survey.

Gain, A. K., Immerzeel, W. W., Sperna Weiland, F. C., and Bierkens, M. F. P. (2011). Impact of climate change on the stream flow of the lower Brahmaputra: trends in high and low flows based on discharge-weighted ensemble modelling. Hydrol. Earth Syst. Sci. 15, 1537-1545. doi: 10.5194/hess-15-1537-2011

Gardner, A. S., Moholdt, G., Cogley, J. G., Wouters, B., Arendt, A. A., Wahr, J., et al. (2013). A reconciled estimate of Glacier 2003 to 2009. Science 340, 852-857. doi: 10.1126/science.1234532

Getirana, A., Kumar, S., Girotto, M., and Rodell, M. (2017). Rivers and floodplains as key components of global terrestrial water storage variability. Geophys. Res. Lett. 44, 359-368. doi: 10.1002/2017GL074684

Hamlington, B. D., Reager, J. T., Chandanpurkar, H., and Kim, K. Y. (2019). Amplitude modulation of season variability in terrestrial water storage. Geophys. Res. Lett. 46, 4404-4412. doi: 10.1029/2019GL082272

IGRAC (2018). Groundwater Overview. UN Water 60.

Koster, R. D., Suarez, M. J., Ducharne, A., Stieglitz, M., and Kumar, P. (2000). A catchment-based approach to modeling land surface processes in a general 
circulation model 1. Model structure. J. Geophys. Res. Atmos. 105, 24809-24822. doi: 10.1029/2000JD900327

Lehner, B., Verdin, K., and Jarvis, A., (2008). New Global Hydrography Derived From Spaceborne Elevation Data. EOS 89, 93-94. doi: 10.1029/2008EO100001

Liang, X., Lettenmaier, D. P., Wood, E. F., and Burges, J. (1994). A simple hydrologically based model of land surface water and energy fluxes for general circulation models. J. Geophys. Res. 99 14415-14428.

Mahmuduzzaman, M., Ahmed, Z. U., Nuruzzaman, A. K. M., and Ahmed, F. R. S. (2014). Causes of salinity intrusion in coastal belt of Bangladesh. Int. J. Plant Res. 4, 8-13. doi: 10.5923/s.plant.201401.02

Massoud, E. C., Purdy, A. J., Miro, M. E., and Famiglietti, J. S. (2018). Projecting groundwater storage changes in California's Central Valley. Sci. Rep. 8:12917. doi: 10.1038/s41598-018-31210-1

Milly, P. C. D., Betancourt, J., Falkenmark, M., Hirsch, R. M., Kundzewicz, Z. W., Lettenmaier, D. P., et al. (2005). Stationarity is dead: whither water management? Science 319, 573-574. doi: 10.1126/science.1151915

Milly, P. C. D., Wetherald, R. T., Dunne, K. A., and Delworth, T. L. (2002). Increasing risk of great floods in a changing climate. Nature. 415, 514-517. doi: $10.1038 / 415514 a$

Nickson, R. T., Mcarthur, J. M., Ravenscroft, P., Burgess, W. G., and Ahmed, K. M. (2000). Mechanism of arsenic release to groundwater, Bangladesh and West Bengal. Appl. Geochem. 15, 403-413. doi: 10.1016/S0883-2927(99)00086-4

Reager, J. T., and Famiglietti, J. S. (2009). Global terrestrial water storage capacity and flood potential using GRACE. Geophys. Res. Lett. 36:L23402. doi: 10.1029/2009GL040826

Richey, A. S., Thomas, B. F., Lo, M. H., Reager, J. T., Famiglietti, J. S., Voss, K., et al. (2015). Quantifying renewable groundwater stress with GRACE. Water Resour. Res. 51, 5217-5238. doi: 10.1002/2015WR017349

Roberts, L. C., Hug, S. J., Dittmar, J., Voegelin, A., Kretzschmar, R., Wehrli, B., et al. (2010). Arsenic release from paddy soils during monsoonflooding. Nat. Geosci. 3, 53-59. doi: 10.1038/ngeo723

Rodell, M., Famiglietti, J. S., Wiese, D. N., Reager, J. T., Beaudoing, H. K., Landerer, F. W., et al. (2018). Emerging trends in global freshwater availability. Nature 557, 651-659. doi: 10.1038/s41586-018-0123-1

Rodell, M., Houser, P. R., Jambor, U., Gottschalck, J., Mitchell, K., Meng, C. J., et al. (2004). The global land data assimilation system. Bull. Am. Meteorol. Soc. 2004, 381-394. doi: 10.1175/BAMS-85-3-381

Rodell, M., McWilliams, E. B., Famiglietti, J. S., Beaudoing, H. K., and Nigro, J. (2011). Estimating evapotranspiration using an observation based terrestrial water budget. Hydrol. Process. 25, 4082-4092. doi: 10.1002/hyp.8369

Rodell, M., Velicogna, I., and Famiglietti, J. S. (2009). Satellite-based estimates of groundwater depletion in India. Nature 460, 999-1002. doi: 10.1038/nature08238

Scanlon, B. R., Zhang, Z., Save, H., Sun, A. Y., Müller Schmied, H., van Beek, L. P. H., et al. (2018). Global models underestimate large decadal declining and rising water storage trends relative to GRACE satellite data. Proc. Natl. Acad. Sci. 115, E1080-E1089. doi: 10.1073/pnas.1704665115

Shamsudduha, M., Taylor, R. G., and Longuevergne, L. (2012). Monitoring groundwater storage changes in the highly seasonal humid tropics: validation of GRACE measurements in the Bengal Basin. Water Resour. Res. 48:W02508. doi: 10.1029/2011WR010993

Siebert, S., Burke, J., Faures, J. M., Frenken, K., Hoogeveen, J., Döll, P., et al. (2010). Groundwater use for irrigation - a global inventory. Hydrol. Earth Syst. Sci. 14, 1863-1880. doi: 10.5194/hess-14-1863-2010

Siebert, S., Henrich, V., Frenken, K., and Burke, J. (2013). Update of the Digital Global Map of Irrigation Areas to Version 5. Institute of Crop Science and Resource Conservation, Land and Water Division, Food and Agriculture Organization of the United Nations, Rome. doi: 10.13140/2.1.2660.6728
Smith, T., and Bookhagen, B. (2018). Changes in seasonal snow water equivalent distribution in high mountain Asia (1987 to 2009). Sci. Adv. 4:e1701550. doi: $10.1126 /$ sciadv. 1701550

Steckler, M. S., Nooner, S. L., Akhter, S. H., Chowdhury, S. K., Bettadpur, S., Seeber, L., et al. (2010). Modeling earth deformation from monsoonal flooding in Bangladesh using hydrographic, GPS, and gravity recovery and climate experiment (GRACE) data. J. Geophys. Res. Solid Earth. 115:B08407. doi: 10.1029/2009JB007018

Tapley, B. D., Bettadpur, S., Ries, J. C., Thompson, P. F., and Watkins, M. M. (2004). GRACE measurements of mass variability in the Earth system. Science 305, 504-505. doi: 10.1126/science.1099192

Tapley, B. D., Watkins, M. M., Flechtner, F., Reigber, C., Bettadpur, S., Rodell, M., et al. (2019). Contributions of GRACE to understanding climate change. Nat. Clim. Chang. 9, 358-369. doi: 10.1038/s41558-0190456-2

Taylor, R. G., Scanlon, B., Döll, P., Rodell, M., Van Beek, R., Wada, Y., et al. (2013). Ground water and climate change. Nat. Clim. Chang. 3, 322-329. doi: $10.1038 /$ nclimate 1744

Thomas, A. C., Reager, J. T., Famiglietti, J. S., and Rodell, M. (2014). A GRACEbased water storage deficit approach for hydrological drought characterization. Geophys. Res. Lett. 41, 1537-1545. doi: 10.1002/2014GL059323

Thomas, B. F., Caineta, J., and Nanteza, J. (2017). Global assessment of groundwater sustainability based on storage anomalies. Geophys. Res. Lett. 44, 11445-11455. doi: 10.1002/2017GL076005

Trenberth, K. E., Dai, A., Van Der Schrier, G., Jones, P. D., Barichivich, J., Briffa, K. R., et al. (2014). Global warming and changes in drought. Nat. Clim. Chang. 4, 17-22. doi: 10.1038/nclimate2067

Vörösmarty, C. J., Green, P., Salisbury, J., and Lammers, R. B. (2000). Global water resources: vulnerability from climate change and population growth. Science 289, 284-288. doi: 10.1126/science.289.5477.284

Voss, K. A., Famiglietti, J. S., Lo, M., De Linage, C., Rodell, M., and Swenson, S. C. (2013). Groundwater depletion in the middle east from GRACE with implications for transboundary water management in the Tigris-EuphratesWestern Iran region. Water Resour. Res. 49, 904-914. doi: 10.1002/wrcr. 20078

Watkins, M. M., Wiese, D. N., Yuan, D. N., Boening, C., and Landerer, F. W. (2015). Improved methods for observing Earth's time variable mass distribution with GRACE using spherical cap mascons. J. Geophys. Res. Solid Earth 120, 2648-2671. doi: 10.1002/2014JB011547

Wiese, D. N., Landerer, F. W., and Watkins, M. M. (2016). Quantifying and reducing leakage errors in the JPL RL05M GRACE mascon solution. Water Resour. Res. 52, 7490-7502. doi: 10.1002/2016WR0 19344

Disclaimer: The views and interpretations in this paper are those of the authors and are not necessarily attributable to ICIMOD, USAID, NASA, or BYU.

Conflict of Interest: The authors declare that the research was conducted in the absence of any commercial or financial relationships that could be construed as a potential conflict of interest.

Copyright (c) 2019 Purdy, David, Sikder, Reager, Chandanpurkar, Jones and Matin. This is an open-access article distributed under the terms of the Creative Commons Attribution License (CC BY). The use, distribution or reproduction in other forums is permitted, provided the original author(s) and the copyright owner(s) are credited and that the original publication in this journal is cited, in accordance with accepted academic practice. No use, distribution or reproduction is permitted which does not comply with these terms. 